\title{
PAINÉIS DESENVOLVIDOS COM RESÍDUO DE GESSO E RESÍDUO DE ALGODÃO: UMA ALTERNATIVA PARA O DESENVOLVIMENTO SUSTENTÁVEL
}

\author{
Ana Paula Kozechen ${ }^{1}$ \\ João Luiz Cuareli Álecio ${ }^{2}$ \\ Rubya Vieira de Campos Mello ${ }^{3}$ \\ Tânia Maria Coelho 4 \\ Celia Kimie Matsuda ${ }^{5}$
}

\begin{abstract}
RESUMO: Atualmente uma grande quantidade de resíduo é descartada no ambiente. Desta forma, o reaproveitamento de resíduos sólidos se torna um dos desafios da atualidade. Este estudo tem como principal objetivo, apresentar uma proposta de um novo produto, aproveitando os resíduos gerados do beneficiamento do algodão bem como o gesso descartado pela construção civil, permitindo uma melhora na qualidade de vida da população em geral, que sofre com descarte inadequado desses resíduos. Para comprovação da qualidade do novo produto, foram realizados ensaios para a caracterização da matéria-prima e desenvolvimento dos painéis conforme metodologia descrita. Os resultados preliminares mostraram que o protótipo do painel, apresentou-se com boa característica visual e com excelente resistência mecânica e ao ataque de fungos, apesar das condições favoráveis. Espera-se assim, chegar a uma alternativa passível de competição no mercado com produtos convencionais, que colabore com a sustentabilidade e seja de baixo custo.
\end{abstract}

Palavras-chave: Resíduo de algodão; Resíduos de gesso; Painéis de gesso.

\footnotetext{
1 Acadêmica de Engenharia de Produção Agroindustrial, Universidade Estadual do Paraná- UNESPAR. anapaulakozechen@hotmail.com.

2 Acadêmico de Engenharia de Produção Agroindustrial, Universidade Estadual do Paraná- UNESPAR. joaocuarelialecio@hotmail.com.com.

${ }^{3}$ Doutoranda em Engenharia Química pela Universidade Estadual de Maringá, Universidade Estadual do Paraná - UNESPAR/Campus de Campo Mourão.rubyadmc@hotmail.com.

4 Doutora em Física pela Universidade Estadual de Maringá, Universidade Estadual do Paraná UNESPAR/Campus de Campo Mourão. coelho.tania@ymail.com.

5 Doutora em Física pela Universidade Estadual de Maringá, Universidade Estadual do Paraná UNESPAR/Campus de Campo Mourão. celia_matsuda@hotmail.com.
}

ReLAInEP - Revista Latino-America de Inovação e Engenharia de Produção, Curitiba, PR, Brasil, v. 3, n. 4, p. 51-61, 2015. 


\section{ReLAInEP}

ABSTRACT: Currently a large amount of waste is discarded into the environment. Thus, the reuse of solid waste becomes one of today's challenges. This study aims to present a proposal for a new product, taking advantage of the waste generated from the processing of cotton and plaster discarded by construction, allowing an improvement in the quality of life of the general population, who suffer from improper disposal of these residues. For the confirmation of the new product quality, tests were conducted to characterize the raw material and development of panels as described methodology. Preliminary results showed that the panel prototype, presented with good visual feature and excellent mechanical strength and fungal attack, despite favorable conditions. This is expected to come up with an alternative subject to market competition with conventional products, to collaborate with the sustainability and is cost effective.

\section{Keywords: Cotton waste; Waste gypsum; Gypsum panels.}

RESUMEN: Actualmente una gran cantidad de residuos se desecha en el medio ambiente. Por lo tanto, la reutilización de los residuos sólidos se convierte en uno de los retos actuales. Este estudio tiene como objetivo presentar una propuesta para un nuevo producto, aprovechando los residuos generados de la transformación de algodón y yeso desechado por la construcción, lo que permite una mejora en la calidad de vida de la población en general, que sufren de la eliminación inadecuada de estos residuos. Para la confirmación de la nueva calidad del producto, se llevaron a cabo pruebas para caracterizar la materia prima y el desarrollo de paneles como metodología descrita. Los resultados preliminares mostraron que el prototipo de panel, presentado con buena función visual y una excelente resistencia mecánica y el ataque de hongos, a pesar de las condiciones favorables. Con ello se espera llegar a una asignatura alternativa a la competencia en el mercado con los productos convencionales, para colaborar con la sostenibilidad y es rentable.

Palabras-clave: Resíduo de algodão; Resíduos de gesso; Painéis de gesso.

\section{INTRODUÇÃO}

Atualmente há uma apreensão globalizada com a gestão ambiental em termos de desenvolvimento sustentável, ou seja, reduzir a emissão de poluentes sejam eles sólidos, líquidos ou gasosos, sem causar danos à evolução econômica. Bardella et al. (2004) enfatiza a adaptação ao modelo de desenvolvimento sustentável, reaproveitando matéria prima de modo a satisfazer as necessidades sem comprometer gerações futuras. Desta maneira o empreendedorismo sustentável encontra-se em notável crescimento, de modo que tem sido valorizado o desenvolvimento de tecnologias e produtos que englobem a utilização de resíduos e a resolução de problemas urbanos e sociais.

As agroindústrias e a construção civil são grandes geradores de resíduos sólidos, respectivamente fibra e gesso. Assim a utilização de tais resíduos relaciona-se com o

ReLAInEP - Revista Latino-America de Inovação e Engenharia de Produção, Curitiba, PR, Brasil, v. 3, n. 4, p. 50-60, 2015. 


\section{ReLAInEP}

empreendedorismo sustentável desenvolvendo placas drywall a partir de materiais reciclados, reduzindo problemas com o descarte de resíduos e de poluição sonora.

A crescente busca pelo desenvolvimento sustentável gera uma preocupação do descarte correto de resíduos gerados, fazendo com que as indústrias da construção civil se preocupem trabalhar com produtos ambientalmente corretos, reduzindo assim os custos com a produção e tornando possível o reaproveitamento desses materiais que antes eram descartados no meio ambiente.

Este estudo tem como objetivo o desenvolvimento de métodos com a finalidade de tratar adequadamente resíduos produzidos em construções civis (gesso) e resíduos das indústrias de beneficiamento do algodão. Grandes problemas ambientais podem ser causados pelo tratamento inapropriado dos resíduos de tais setores. Reaproveitando esses resíduos, o intuito maior é o de desenvolver painéis que poderão ser utilizadas na construção civil. Esses painéis compósitos serão fabricados usando o gesso reciclado e fibras de algodão, especificamente resíduo de filtro do beneficiamento do algodão.

Assim transformando os resíduos gerados pelo homem em um produto sustentável, que poderá trazer vantagens ao ambiente, ao desenvolvimento da construção civil e a sociedade. $\mathrm{O}$ desenvolvimento desses painéis, busca a possibilidade de oferecer ao mercado um novo produto com qualidade, baixo custo e que contribua para o desenvolvimento sustentável.

\section{FUNDAMENTAÇÃO TEÓRICA}

\subsection{Resíduo do algodão}

O algodão é uma planta originária do continente americano, inclusive no território brasileiro, utilizada há muito tempo pelos indígenas em cultivos regulares. Para o Brasil, tornou-se importante produto de exportação após 1760, quando foi disseminado pelo seu território, notadamente no Nordeste, com plantios na Bahia, Pernambuco e Maranhão (URBAN et al., 1995).

A principal produção do algodoeiro é o fruto e sua massa é composta pelas sementes (52\%), fibras (40\%) e demais estruturas botânicas (8\%). As sementes contêm aproximadamente $15 \%$ de óleo, $3 \%$ de fibras, $40 \%$ de proteínas e $40 \%$ de tegumentos. Já as fibras, estruturas compostas por camadas de celulose, são o principal produto econômico do

ReLAInEP - Revista Latino-America de Inovação e Engenharia de Produção, Curitiba, PR, Brasil, v. 3, n. 4, p. 50-60, 2015. 


\section{ReLAInEP}

algodoeiro (BATALHA; BUAINAIN, 2007 apud BELTRÃO, 1999; GARCIA-LORCA; CARNERO, 1991).

Dentre os principais usos da fibra de algodão, incluem-se móveis, aplicações médicas, na indústria automobilística e em varias outras indústrias, no entanto o principal consumo é para a fiação destinada a indústria têxtil, que absorve aproximadamente $60 \%$ da produção mundial de fibra de algodão (BATALHA; BUAINAIN, 2007 apud UNCTAD, 2005).

Nos diversos processos da indústria têxtil são gerados diferentes tipos de resíduos com diferentes composições químicas. Os resíduos de algodão secos gerados na fiação e na tecelagem equivalem a aproximadamente $8 \%$ do total do algodão. Esses resíduos são inconvenientes por ocuparem grandes espaços físicos e representarem um sério problema devido ao grande excedente acumulado nos aterros industriais, o que diminui consideravelmente a vida útil dos mesmos (HOLTZ, 2008).

Grande volume dos resíduos gerados hoje pela indústria de fios consiste nos subprodutos de material têxtil - conhecidos como Piolho, Estopa e Varredura - que já vêm sendo comercializados como resíduos de alto valor agregado com empresas do ramo têxtil.

Outro tipo de resíduo gerado no processo industrial, em quantidades razoáveis, é o chamado Pó de filtro - resultante dos processos de limpeza das fibras e filtragem do ar (tratamento das emissões atmosféricas) (PAGANNI; EURICH; FRANCO, 2011).

\subsubsection{Resíduo de algodão: pó de filtro}

Na fiação, o algodão é processado nos abridores, batedores, cardas, passadores, penteadeiras, maçaroqueiras, filatórios, retorcedeiras e conicaleiras. Nessa sequência de processos são eliminadas folhas, sementes e impurezas. As microfibras soltas do processo de fiação são sugadas por tubulações e enfardadas junto com as folhas e sementes e são consideradas resíduo de algodão (HOLTZ et al., 2009).

Na limpeza, que ocorre nos batedores, são eliminados corpos estranhos contidos no algodão (cascas, poeiras, galhos, sementes, entre outras) por meio da ação da força centrífuga. Seguido da fibra (material mais leve) que é eliminada pelo fluxo de corrente de ar e as impurezas caem, sendo depositadas, para depois serem aspiradas para uma central de filtros. Este material coletado dos filtros consiste no resíduo denominado pó de filtro (SILVA, 2009).

ReLAInEP - Revista Latino-America de Inovação e Engenharia de Produção, Curitiba, PR, Brasil, v. 3, n. 4, p. 50-60, 2015. 


\section{ReLAInEP}

Já a carda tem como objetivo a abertura, limpeza, cardação ou alinhamento (separação das fibras quase que individualmente) e estiramento das fibras (afinar o produto). Tendo como produto de saída a fita da carda. Com a separação das fibras, são liberadas ainda grandes quantidades de impurezas, que são encaminhadas aos filtros, também gerando o Pó de Filtro (PAGANNI; EURICH; FRANCO, 2011).

Neste mesmo processo de separação, são eliminadas as fibras que, por suas características físicas, podem prejudicar a qualidade do fio a ser produzido. Sua função é de uniformizar o peso/unidade de comprimento, estirar (afinar o produto) e promover a mistura do material. Os objetivos são a paralelização das fibras provenientes das cardas, a regularização das massas por unidade de comprimento (por dublagem e estiragem), e a melhora da mistura de fibras. Neste processo também é gerado o Pó de Filtro (PAGANNI; EURICH; FRANCO, 2011).

\subsection{Resíduo da construção civil}

A indústria da construção civil é um importante segmento da indústria brasileira, tida com um indicativo do crescimento econômico e social. Porém também uma atividade geradora de grandes impactos ambientais (FERNANDEZ; ROMA; MOURA, 2011).

A Resolução da CONAMA 307/2002 define resíduos da construção da seguinte maneira:

\footnotetext{
Resíduos da construção civil são as provenientes de construções, reformas, reparos e demolições de obras da construção civil, e os resultantes da preparação e da escavação de terrenos, tais como: tijolos, blocos cerâmicos, concreto em geral, solos, rochas, metais, resinas, colas, tintas, madeiras e compensados, forros, argamassa, gesso, telhas, pavimento asfáltico, vidros, plásticos, tubulações, fiação elétrica etc., comumente chamados de entulhos de obras, caliça ou metralha.
}

Segundo Karpinski et al. (2009) o grande volume de materiais de construção e de atividades nos canteiros de obras acaba gerando um elevado índice de resíduos produzidos nas áreas urbanas. Esses resíduos comprometem a paisagem urbana, invadem pistas, dificulta o tráfego de pedestres e de veículos, como também a drenagem urbana; além de propiciar a atração de resíduos não inertes, com multiplicação de vetores de doenças e degradação de áreas urbanas, o que afeta a qualidade de vida da sociedade como um todo.

Uma alternativa para a solução desse problema é a reciclagem, pois a reciclagem deste tipo de resíduos apresenta vantagens econômicas, sociais e ambientais, como: economia para as prefeituras em decorrência da diminuição do volume de resíduos a ser coletado e

ReLAInEP - Revista Latino-America de Inovação e Engenharia de Produção, Curitiba, PR, Brasil, v. 3, n. 4, p. 50-60, 2015. 


\section{ReLAInEP}

depositado em locais adequados; para o construtor, que pode executar obras a menores custos utilizando materiais reciclados; minimização de áreas para aterro sanitário; redução dos custos dos materiais de construção oriundos da reciclagem e preservação do meio ambiente natural (FREITAS, 2009).

O gesso é uma matéria prima muito utilizada na construção civil, com um alto índice de descarte no ambiente. O gesso é comumente utilizado para a execução de revestimentos, em blocos e painéis de vedação, forros, e como elemento decoração nas construções (Ribeiro, 2006). De acordo com Ahmed et al. (2011) são gerados cerca de 15 milhões de toneladas de resíduos de gesso anualmente no mundo.

Segundo dados da CNI - Confederação Nacional da Indústria (2010) o faturamento anual da indústria de gesso brasileira gira em torno de US\$ 300 milhões/ano.

Sendo assim fica caracterizada a importância da reciclagem do gesso. Após diversos estudos, CONAMA (2011) publicou a Resolução no. 431 alterando a classificação do gesso como "resíduos recicláveis", de modo que sua reciclagem é feita através da moagem e calcinação de tais resíduos reduzindo a poluição por meio de dejetos sólidos conjuntamente com um decréscimo na extração deste recurso.

\subsection{Painel de gesso acartonado}

O gesso acartonado, também conhecido como drywall é um sistema construtivo que surgiu basicamente para substituir as paredes internas de tijolos e blocos bem como esconder tubulações e dutos na construção civil (FERREIRA, 2007).

Segundo Losso e Viveiros (2004) o gesso acartonado está se destacando no mercado da construção civil nacional. O material forma um sistema construtivo de vedações interno também chamado de "sistema construtivo a seco". Apesar de estar presente desde 1972, o gesso acartonado começou a ganhar expressiva importância no Brasil na segunda metade da década de 1990.

A utilização de painéis de gesso acartonado na construção civil, aumentou nos últimos anos por diversos fatores, entre eles a facilidade e a rapidez na instalação por ser um processo de construção a seco Magalhães e Almeida (2010).

Segundo Castro (2007), a aplicação dos painéis de gesso acartonado (drywall) vem crescendo cada vez mais no Brasil, e destaca:

De todas as inovações introduzidas na construção brasileira, sem dúvida os sistemas

ReLAInEP - Revista Latino-America de Inovação e Engenharia de Produção, Curitiba, PR, Brasil, v. 3, n. 4, p. 50-60, 2015. 


\section{ReLAInEP}

drywall são os que mais rapidamente vêm ganhando espaço no País. De início, foram aplicados em edificações comerciais - prédios de escritórios, hotéis, flats, cinemas, casas de espetáculos, shopping centers, hospitais e escolas, entre outros - e nos últimos anos vêm tendo utilização crescente também em prédios residenciais, notadamente por iniciativa das incorporadoras e construtoras líderes de mercado das capitais e principais cidades em especial das regiões Sudeste e Sul.

Os painéis de gesso acantonado podem ser ainda melhores do que paredes de alvenaria, quando utilizadas configurações multicamadas, juntamente com material fibroso (LOSSO; VIVEIROS, 2005).

\section{METODOLOGIA}

A pesquisa é considerada como bibliográfica, ou seja, a metodologia e técnicas utilizadas para o desenvolvimento dos painéis serão baseadas em pesquisas e materiais bibliográficos existentes na literatura. Quanto aos procedimentos técnicos a pesquisa se classifica como experimental. As placas foram confeccionadas nos Laboratórios de Química e Física Aplicada da UNESPAR/FECILCAM.

A parte experimental do trabalho foi dividida em duas etapas, o desenvolvimento do protótipo do painel e ensaios para a avaliação dos mesmos.

Na primeira etapa foi realizada a reciclagem do gesso, sendo este coletado de entulhos da construção civil. O processo teve inicio com a retirada de grande parte de sua umidade dos resíduos de gesso e posteriormente com a sua reidratação. Através de testes concluiu-se que a temperatura de secagem, para a reciclagem, de $150^{\circ} \mathrm{C}$ forneceu resultados de propriedades físicas similares as do gesso comercial, e que estão de acordo com dados encontrados na literatura (HERMES, 2011).

Depois de seco, seguiu para a moagem sendo submetido a duas operações num moinho de disco, a primeira moeu os blocos maiores $(1$ a $5 \mathrm{~cm}$ ) transformando-os em sólidos granulares (de 0,5 a $10 \mathrm{~mm}$ ) e a segunda os converteu em pó (de $1 \mu \mathrm{m}$ até $0,5 \mathrm{~mm}$ ), possibilitando a peneiração. As partículas do pó passaram por uma peneira de aço inox, mesh 60, cuja abertura é de $0,250 \mathrm{~mm}$, essa etapa padronizou o tamanho das partículas, possibilitando a peneiração, o pó que passar pela peneira estará pronto para a fase de reidratação.

ReLAInEP - Revista Latino-America de Inovação e Engenharia de Produção, Curitiba, PR, Brasil, v. 3, n. 4, p. 50-60, 2015. 


\section{ReLAInEP}

O processo de fabricação dos painéis consistiu em misturar o gesso, a fibra e demais aditivos, em quantidades que foram baseados na metodologia do painel de gesso acartonado original.

Assim para fabricar os protótipos dos painéis foram utilizados 50 gramas da fibra de algodão, 1,2 litros de água e 500 gramas de gesso reciclado, todos misturados em um liquidificador. Após a mistura ser realizada e formar uma pasta homogênea foi então depositada em um molde de placa quadrado de aço, forrados com papel cartão e cobertos pelo mesmo papel cartão, caracterizando-se assim o painel de gesso acartonado. Os protótipos dos painéis ficaram em repouso por cinco dias até que o gesso estivesse totalmente seco. A Figura 1 mostra o protótipo do painel desenvolvido.

Figura 1 - Placa de gesso e fibra

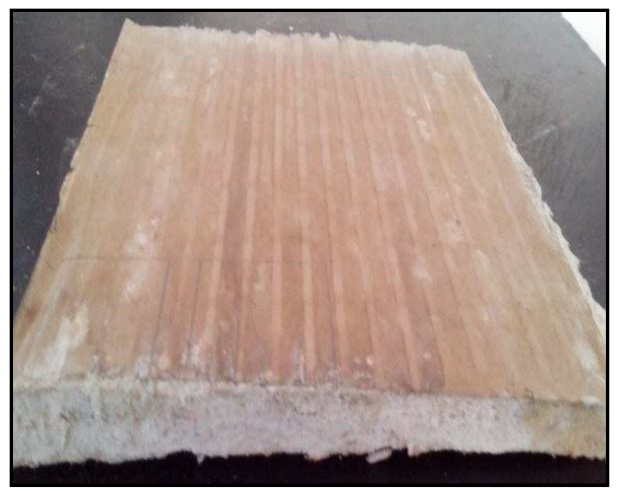

Fonte: Elaborado pelo autor

A segunda etapa incluiu a avaliação do desempenho do protótipo do painel já fabricado, no qual foi realizado o ensaio de ataque por fungos, sendo feitos em amostras de tamanho $5 \mathrm{~cm} \times 5 \mathrm{~cm}$, como mostra a Figura 2. As amostras foram acondicionadas por 48 horas, em estufa a temperatura de $23 \pm 2^{\circ} \mathrm{C}$ e UR de $50 \%$ e após esse período, as mesmas foram avaliadas visualmente.

Figura 2 - Amostras do painel para ensaio de ataque por fungos

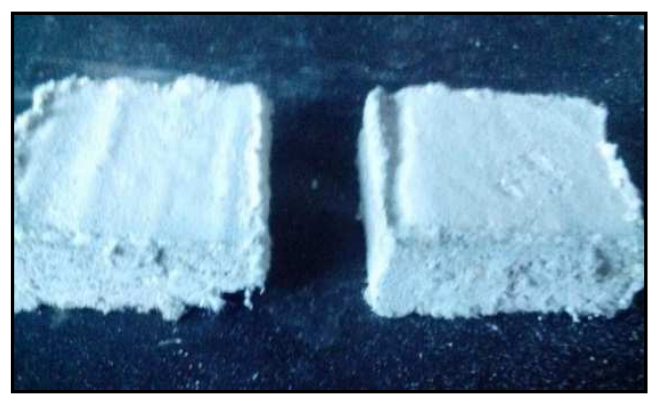

Fonte: Elaborado pelo autor

ReLAInEP - Revista Latino-America de Inovação e Engenharia de Produção, Curitiba, PR, Brasil, v. 3, n. 4, p. 50-60, 2015. 


\section{ReLAInEP}

As avaliações preliminares do estudo que ainda está em desenvolvimento foram bons, os protótipos apresentaram uma boa característica visual e física.

\section{RESULTADOS E DISCUSSÕES}

O resultado do ensaio de ataque por fungos foi positivo, pois no presente ensaio a UR dentro da estufa era próxima a $65 \%$ e a temperatura passava dos $20{ }^{\circ} \mathrm{C}$. Mesmo com essas condições favoráveis ao ataque de fungos, as placas resistiram não sofrendo alterações. Após 48 horas de permanência das amostras dos painéis na estufa com umidade relativa de $50 \%$, foi possível analisar por meio de uma análise visual, que não houve aparecimento de colônias de fungos como pode ser visualizado na Figura 3.

Figura 3 - Amostras do painel após ensaio de ataque por fungos

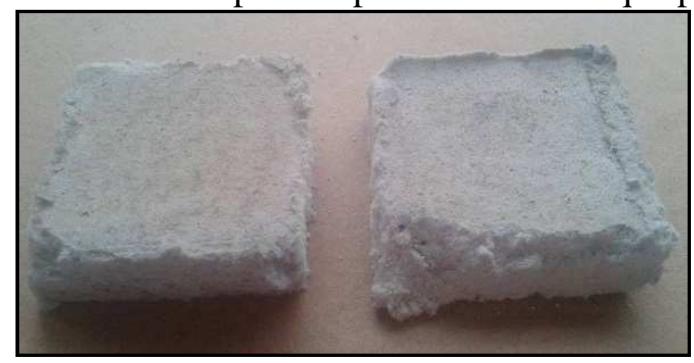

Fonte: Elaborado pelo autor

As avaliações preliminares do estudo, ainda em desenvolvimento, foram consideradas satisfatórias, os protótipos apresentaram uma boa característica visual e com excelente resistência mecânica quando comparados a paineis comerciais, tornando o produto promissor e também com grande interesse do ponto de vista ambiental.

\section{CONSIDERAÇÕES FINAIS}

O desenvolvimento dos protótipos dos painéis apresentou bons resultados iniciais quanto à aparência, livre de odores e mostrando resistência a fungos. Essas são características muito importantes para um produto que posteriormente poderá ser utilizado na construção civil.

Espera-se que esse método de produção de material alternativo, conduzido de forma sistêmica, e embasado por uma tecnologia apropriada à realidade socioeconômica local, poderá contribuir para a engenharia e para o desenvolvimento sustentável.

O estudo ainda está em fase de aprimoramento do processo de reciclagem dos resíduos e do processo de produção. Sugere-se que novos ensaios também sejam realizados como

ReLAInEP - Revista Latino-America de Inovação e Engenharia de Produção, Curitiba, PR, Brasil, v. 3, n. 4, p. 50-60, 2015. 
ensaios físicos e químicos, assim como, ensaio de flamabilidade, já que atualmente para a construção civil a questão de produtos com propriedades antichamas é cada vez mais requisitada pelo mercado.

\section{REFERÊNCIAS}

AHMED A.; UGAI, K.; KAMEI T. Investigation of recycled gypsum in conjunction with waste plastic trays for ground improvement. Construction and Building Materials, v.25, n.1, p. 208-217. jan. 2011. Disponível em: <http://www.sciencedirect.com/science/article/pii/S0950061810002850>

BATALHA, M. O.; BUAINAIN, A. M. Cadeia produtiva do algodão. Brasília: MAPA, 2007.

CASTRO, M. Sistemas industrializados promovem salto qualitativo na construção civil brasileira. 2007. Disponível em: <http://www.drywall.org.br/artigos.php?pagina=16>. Acesso em: 24 set. 2015.

CNI - Confederação Nacional da Indústria. Oportunidades de eficiência energética para a Indústria: relatório setorial: cal e gesso. Brasília: CNI, 2010. 42 p. (Relatório setorial, ISBN 978-85-7957-016-2)

CONAMA. Conselho Nacional do Meio Ambiente. Resolução nº 431, de 24 de maio de 2011. Brasília. Diário Oficial da União, Publicada no DOU n ${ }^{\circ} 99$, de 25 de maio de2011, p. 123.

CONAMA. Resolução $\mathbf{n}^{\mathbf{0}} \mathbf{3 0 7}$, de 5 de julho de 2002. Disponível em: <http://www.mma.gov.br/port/conama/res/res02/res30702.html>.

FERNANDEZ, J. A. B.; ROMA, J. C.; MOURA, A. M. M. Resíduos da construção civil. 2011.

FERREIRA, C.G.Estudo comparativo de desempenho de paredes e forros de gesso acartonado. Trabalho de Graduação. Departamento de Engenharia Civil, Universidade Anhembi Morumbi, São Paulo 2007.

FREITAS, M.I. Os resíduos de construção civil no município de Araraquara/SP. 2009, 86p. Dissertação de mestrado apresentada ao Centro Universitário de Araraquara - UNIARA, Araraquara-SP.

HOLTZ, M. et al. Cultivo de Pleurotus ostreatus utilizando resíduos de algodão da indústria têxtil. Revista de Ciências Ambientais, v. 3, n. 1, p. 37-57, 2009.

HOLTZ, M. Utilização de resíduos de algodão da indústria têxtil para a produção de corpos frutíferos de Pleurotus ostreatus DSM 1833. 2008. 102 p. Dissertação (Mestrado em Engenharia de Processos) - Universidade da Região de Joinville, Joinville, 2008.

ReLAInEP - Revista Latino-America de Inovação e Engenharia de Produção, Curitiba, PR, Brasil, v. 3, n. 4, p. 50-60, 2015. 


\section{ReLAInEP}

KARPINSKI, L. A. et al. Gestão diferenciada de resíduos da construção civil: uma abordagem ambiental. Porto Alegre: EDIPUCRS, 2009.

LOSSO, M.; VIVEIROS, E. Sound insulation of gypsum board in practice. In: The 2005 Congress and Exposition on Noise Control Engineering, 2005, Rio de Janeiro. Anais... Rio de Janeiro.

MAGALHÃES, A. C. T. V.; ALMEIDA, J. G. The use of cactus mucilage in gypsum plaster: effects in water absorption and static flexion strength. Ambiente Construído, Porto Alegre, v. 10, n. 1, p. 139-151, jan./mar. 2010.

PAGANNI, N. C.; EURICH, V. R. P.; FRANCO, J. M. Gerenciamento De Resíduos Sólidos De Indústria De Fios Em Cooperativa Agroindustrial. In Congresso brasileiro de gestão ambiental, 2, 2011, Londrina. Anais... Londrina.

RIBEIRO, A. S. Produção de gesso reciclado a partir de resíduos oriundos da construção civil. 2006. 86 p. Dissertação (Mestrado em Engenharia Urbana) - Universidade Federal da Paraíba, João Pessoa, 2006.

SILVA, A. N. Valorização de resíduos têxteis. 2009. 105 p. Dissertação (Mestrado em Gestão Ambiental) - Universidade do Minho, 2009.

URBAN et al., Desenvolvimento da produção de têxteis de algodão no Brasil. Informações Econômicas. São Paulo. SP, v. 25, n. 12, 1995.

ReLAInEP - Revista Latino-America de Inovação e Engenharia de Produção, Curitiba, PR, Brasil, v. 3, n. 4, p. 50-60, 2015. 

Brasil, v. 3, n. 4, p. 50-60, 2015. 